\title{
Pneumonia due to aspiration of povidine iodine after preoperative disinfection of the oral cavity
}

\author{
Takashi Hitosugi $^{1}$ (D) Masanori Tsukamoto ${ }^{2}$ (D) $\cdot$ Takeshi Yokoyama $^{1}$ (D) \\ Received: 22 May 2019 / Accepted: 11 September 2019 / Published online: 1 November 2019 \\ (C) Springer-Verlag GmbH Germany, part of Springer Nature 2019
}

\begin{abstract}
Introduction Povidone-iodine (PI) is thought to be an effective disinfectant and safe for many surgeons. Aspiration pneumonia is usually caused by gastric contents, but if PI solution will be aspirated, pneumonia or other complications may occur.

Case report We present a case of pneumonia to aspiration of PI solution in a 91-year-old man patient who underwent oralmaxillofacial surgery. When surgeons used PI solution for disinfection into the oral cavity, the solution seems to be sinking gradually. The patient showed severe respiratory distress and developed hypoxia. There were much frothy fluids into a tracheal tube. We suctioned through the endotracheal tube and performed bronchoscopy, that revealed a redness which appeared associated to a chemical injury on the left trachea and bronchus. His condition was complicated by ARDS and DIC. Periodical bronchial suction and guideline-based treatments of ARDS were carried in ICU. He recovered without severe complication. Conclusion Although PI solution for an oral disinfection is used routinely, all operators need to be aware of the risk for PI aspiration
\end{abstract}

Keywords Aspiration pneumonia $\cdot$ Povidone iodine (PI) $\cdot$ Disseminated intravascular coagulation (DIC) $\cdot$ Adult respiratory distress syndrome (ARDS) · Positive end-expiratory pressure (PEEP)

\section{Introduction}

Povidone-iodine (PI) is a traditionally and commonly used for oral disinfection before oral-maxillofacial surgery [1-3]. PI is thought to be a safe and effective disinfection, but it involved the risk of severe complications from its aspiration that may occur [4-6]. In vivo study, various concentrations of a pulmonary instilled PI solution can induce lung injury in rats, as a result of the atelectasis and the concomitant occurrence of

Takashi Hitosugi

hitosugi.takashi.724@m.kyushu-u.ac.jp

Masanori Tsukamoto

tsukamoto@dent.kyushu-u.ac.jp

Takeshi Yokoyama

yokoyama@dent.kyushu-u.ac.jp

1 Department of Dental Anesthesiology, Faculty of Dental Science, Kyushu University, 3-1-1, Maidashi, Higashi-ku, Fukuoka 812-8582, Japan

2 Department of Dental Anesthesiology, Kyushu University Hospital, 3-1-1, Maidashi, Higashi-ku, Fukuoka 812-8582, Japan death [7]. We present a case of pneumonia secondary to aspiration of PI solution used as an oral antiseptic (Fig. 1).

\section{Case report}

A 91-year-old male patient (45 kg in weight and $157 \mathrm{~cm}$ in height) visited our hospital due to left maxillary recurrent gingival cancer. The patient had not contained special features in preoperative examinations, and no history of pulmonary disease. His ASA physical status was class II. The patient was given induction of anesthesia with $0.6 \mathrm{mg} / \mathrm{kg}$ midazolam and $0.6 \mathrm{mg} / \mathrm{kg}$ rocuronium. An endotracheal tube (PORTEX®, Saint Paul, MI, USA: an internal diameter of $6.5 \mathrm{~mm}$ ) was nasal-intubated with a bronchoscopy. Seven milliliters of air was inserted into the cuff. The tracheal tube was fixed at the $28 \mathrm{~cm}$ at left nostoril. Tidal volume and respiration rate were maintained at $8 \mathrm{ml} / \mathrm{kg}$ and 10 per minute. Peak inspiratory pressure was $15 \mathrm{~cm} \mathrm{H}_{2} 0$. Anesthesia was maintained by $1 \mathrm{~L} /$ min of $\mathrm{O} 2,1 \mathrm{~L} / \mathrm{min}$ of air, $0.8-1.5 \%$ of sevoflurane, and 0.3 $0.8 \mathrm{mg} / \mathrm{kg} / \mathrm{min}$ of remifentanil, BIS was 38-51. The cuff of the tracheal tube was maintained at $20-25 \mathrm{mmHg}$. After selective neck dissection, povidone iodine (PI: ISODINE®SOLUTION 10\%, Shionogi, Japan) was used 


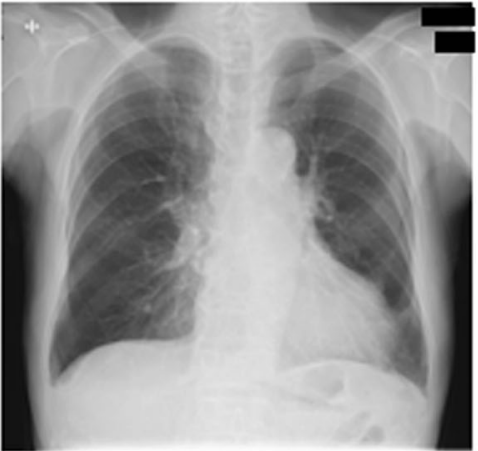

Pre operation

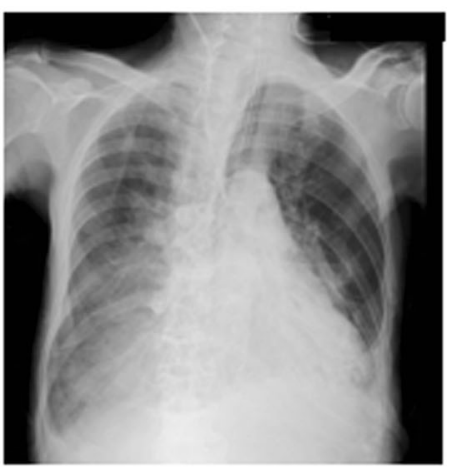

POD: 2

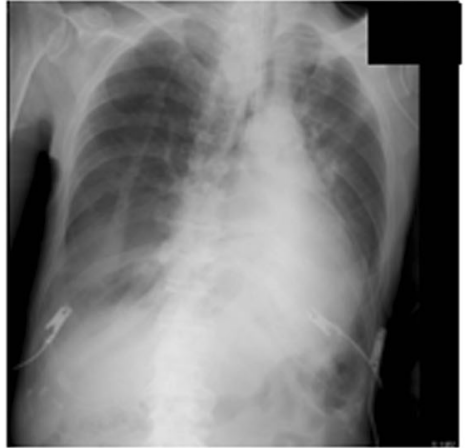

Operation theater

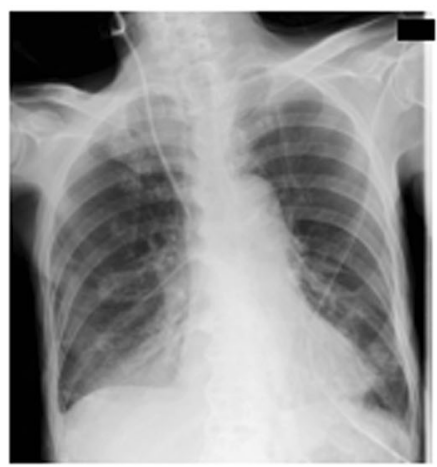

POD: 4

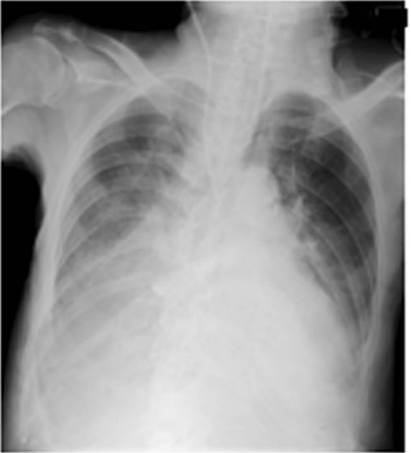

ICU

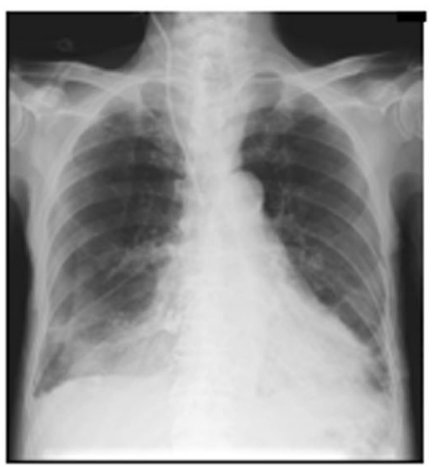

POD: 6

Fig 1 Series of chest x-ray. Pneumonic infiltration and atelectasis shown on left lower lung field in an operating theater. POD 6, left lung field shows nearly normalizing. (POD postoperative day)

for oral disinfection about $20 \mathrm{ml}$, and $20 \mathrm{ml}$ of normal saline was used for irrigation. During an irrigation of oral cavity, gradually, the PI solution-level was shown slowly lower and decreased by half. Surgeons drew all PI solution inside the oral cavity with a suction catheter. How much the amount of PI solution was not known. After 2 min, a capnography demonstrated an obstructive pattern. Some short while later, oxygen saturation suddenly declined from 100 to $96 \%$. He had an inadequate pulmonary ventilation and increasing resistance with ventilation-bag. But, there were no flexion or obstruction of ET tube, and a rale or an abnormal respiratory sound were not heard from the lung. BIS marked 40 45 and a pressure inside the ET tube of cuff was $26 \mathrm{mmHg}$. The operation was stopped immediately. We tried to suctioning through the ET tube. A frothy and slightly brownish-tinged sputum extracted $2 \sim 5 \mathrm{ml}$ only. A minute later, a lung compliance and a chest movement restored to normal. Electrocardiograph showed a normal sinus rhythm. An arterial catheter was inserted into the left radial artery for continuous arterial blood gas analyses. Respiratory rale or murmur were not heard from both lungs on auscultation, and pulse oxygen saturation was $100 \%$. An air leakage did not occur, and maximum inspiratory pressure was $17 \mathrm{cmH}_{2} \mathrm{O}$, while conducting mechanical ventilation with $10 \mathrm{cmH}_{2} \mathrm{O}$ of positive end-expiratory pressure (PEEP). Ninety minutes after, the operation was finished. A rale was heard from the left lung. When we suctioned through the ET tube, there were much light-pink frothy fluid. We attempted a bronchoscopy and suctioning of the spectrum constantly which spurted from left tracheobronchial tree with a bronchoscopy. But it did not seem to decrease a volume of that. There was redness which appeared associated like a chemical injury on left trachea and bronchus. At the time, arterial blood gas analysis was as follows: $\mathrm{FiO}_{2} 0.5, \mathrm{pH} \mathrm{7.42,} \mathrm{PaO}_{2} 85.4 \mathrm{mmHg}$, $\mathrm{PaCO}_{2} 41.1 \mathrm{mmHg}$, and $\mathrm{SaO}_{2} 96.4 \%$. A chest X-ray demonstrated interstitial opacities with atelectasis localized the left mid to the lower lung, and was conducted on suspicion of aspiration pneumonia. According to the disease trajectory, specific clinical symptoms, and several examination results, we suspected the aspiration of PI solution during oral irrigation. When the patient's spontaneous respiration recovered, light-pink frothy sputum was still much discharging. The patient could not be extubated and was transferred to the intensive care unit (ICU) for additional treatments. His condition was complicated further by the presence of hypoxemia, noncardiac pulmonary edema, disseminated intravascular coagulation (DIC), and acute respiratory distress syndrome (ARDS). A decision was made to treat the patient with follow-up guideline of DIC and ARDS. These treatments were sedation, prone position, PEEP, inhaled NO, and intravenous antibiotics which were administered, and additional 
suction of lung was attempted using bronchoscopy. Days later, the amount of frothy secretions from a left of tracheobronchial tree was decreased gradually. A chest X-ray examination and arterial blood gas analysis showed significant improvement. The patient was weaned from the ventilator on day 6 and discharged from the ICU on day 7; the man was transferred to a general ward without residual damage.

\section{Discussion}

Aspiration pneumonia occurs anytime in the perioperative period. That is known to occur when the $\mathrm{pH}$ of gastric contents is 2.5 or less and the amount of contents is $20 \mathrm{ml}(0.3 \mathrm{ml} / \mathrm{kg})$ or more. Even if the $\mathrm{pH}$ is over 2.5, the complication can occur depending on ingredients of the contents [7-9]. During anesthesia, the occurrence of rate is $10 \%$, about one in 3000 cases, and it accounts for $10-30 \%$ of anesthesia-related deaths. It mainly occurs during removal of a tracheal tube (35.9\%) [10]. But, the incident rate of aspiration pneumonia during operation is still not known.

Oropharyngeal secretions leak through the cuff of these folds, increasing the risk of aspiration pneumonia [11]. Air leakage after tracheal intubation can occur for many reasons, for example, low pressure inside the cuff of tracheal tube, rupture of the cuff, and when the cuff will be hang around vocal cords. Types of air leakage with a cuff can differ according to the type of tube. In recent years, the design of cuff had been considerably improved to seal on the surface of tracheal mucosa. The newly introduced tapered-shaped tracheal tube cuff made from polyurethane (PU) represents a new strategy to reduce fluid leakage across the cuff. The tapered cuff design ensures that there is always a sealing zone where the outer cuff diameter corresponds to the internal tracheal diameter. The fluid leakage in the new tapered-shaped PVC was made from PU against the classic cylindrical shaped PU which was made from polyvinylchloride (PVC). The tapered-shaped PVC tube cuff was more efficient than the cylindrical shaped PU in preventing subglottic fluid leakage [12]. Though, if fluid will accumulate above the cuff, every cuff could not prevent a leakage. In vitro study, almost every fluid will leak through PVC cuffs of these folds within only 5 min [12]. Specific recommendations for an efficient cuff are not still available. Because the determinant elements of a proficient cuff design are unidentified. In our case, we used a tapered-shaped PVC tube cuff and measured the pressure with a control inflator. There was no air leakage during operation, and a rupture was not discovered in the cuff after removal of the tracheal tube at the ICU. Accordingly, we surmise that some amounts of PI solution pooled above the cuff; the cuff could not prevent that, which in turn caused the aspiration pneumonia.
PI is widely used as a perioperative antiseptic to disinfect the oral cavity before maxillofacial surgery. A $10 \%$ PI (pH 5.0) solution generally contains $1 \%$ available iodine and iodide, and is a potent bactericidal solution that does not irritate the oral mucosa [13]. Although, a 5\% PI solution is thought to be a safe and effective antiseptic when used on skin and mucous membranes [14]. A previous study reported that PI cytotoxicity occurs in a dose- and treatment time-dependent manner, and when PI was not cytotoxic, it induces inhibition of DNA, cellular RNA, and protein synthesis, even at doses and treatment times [7]. Many oral-maxillofacial surgeons prefer to irrigate an oral cavity with PI solution. However, controversy still exists regarding preoperative intraoral preparations [15-18]. The appropriate preoperative treatment of the oral cavity has no definitive answer still now. Most surgeons recognize that regardless of pathogenicity, increased bacterial loads are associated with an increased risk of infection. The bacterial flora of saliva is highly variable and is composed of potentially pathogenic species, with counts in the range of $10^{7}$ to $10^{8}$ per milliliter [16]. Another study further demonstrates that PI preparation can result in a significant reduction in intraoral bacterial counts to levels as low as $10^{4}$, which is persistent throughout the course of most surgical procedures in elective intraoral surgery [18]. The second most commonly used intraoral preparation is saline-only. Other report had found no difference in infection rates between preoperative preparation with normal saline versus PI solution [15]. Furthermore, preoperative preparation with saline results in an increase in intraoral bacterial counts [19]. Some authors report that isolation of oral pathogens is not correlated with a greater risk of wound infection [17]. Another studies have showed that, compared with no preparation, use of a PI solution can diminish the incidence of postoperative wound complications [20]. Although it is not known exactly how the effectiveness of an oral disinfection, we suggest that because of the significant reduction in bacterial counts after oral disinfection with PI, the use of the disinfection "may reduce" surgical wound infections. Though, there is not yet clearly evidence for the efficacy of oral disinfection, we should be considered when: (1) patients have a cardiovascular disorder, valvular disease, history of congenital heart defects; (2) implanting any alloplastic material; (3) utilizing nonvascularized bone grafts; (4) operating on immunosuppressed patients, including the elderly, those with concurrent systemic illnesses, diabetics, and patients with a history of prior radiotherapy; and (5) oral hygiene is suboptimal [18].

Only few cases reported in which patients developed aspiration pneumonia from PI after preparation to disinfection of the oral cavity. In the first report [4], about 5 min after completing the oral disinfection with PI (5\%), rales were heard bilaterally in the upper lung. The patient was mechanically ventilated in the ICU for $30 \mathrm{~h}$. X-ray of the chest revealed clearing of the upper lobe infiltrates 5 days after 
the aspiration, and the patient recovered without any complications. In the second report [5], the patient suffered pneumonia after PI $(0.7 \%)$ aspiration. Aspiration was caused by an insufficient seal of the tube cuff. The patient improved during the following 1 week. In the last orofacial surgery case [6], during irrigation of oral cavity, bubbles formed in the mouth. The pneumonia was caused by aspiration of PI (10\%) secondary solution. The tracheal tube cuff was damaged and made a hole, when that was fastened by wire. During the operation, oxygen saturation declined and a rale was heard. A tracheal suction was commenced; mechanical ventilation with PEEP and periodical bronchial toilet with bronchoscopy were carried. Bronchodilators, antibiotics, steroids, and diuretics were also used to treat the pneumonia. Fifty hours after the operation, the patient was transferred to a general ward without any complication.

In vivo study [7] found that the rats whose lungs were instilled with $0.5 \mathrm{ml}$ of $5 \%$ PI solution died, whereas same volume of solution less than $1 \%$ survived. Although, they presume that this difference was the result of differences in the severity of the injury to the alveolar capillary network after PI instillation. They suggest that the severity and extent of PIinduced lung injury are dependent on the PI dose, and PI solution causes pulmonary edema immediately after its instillation; the edema resolves with time. However, the instillation of PI also elicits an inflammatory reaction in the lungs with leukocyte infiltration and results in atelectasis within $1 \mathrm{~h}$ after its instillation. With time, this inflammatory response progressively dissipates, and the resultant lung lesion is scar tissue.

The most important treatment for aspiration pneumonia is suction of aspirated contents [21]. One of the options is to switch the patient to a lateral position and to administer chest percussion [22]. Next, we should perform with mechanical ventilation with PEEP. The treatment minimizes the damage of alveoli [23]. If patients show symptoms of clinical infection, antibiotics should be administered. And to prevent pulmonary edema, proper use of steroids is recommended. Its beneficial effects usually appear 3 days after initial administration. In addition, restriction of fluid provision and diuretics helps patients recover pulmonary function $[24,25]$. In our case, when oxygen saturation decreased during the operation, we confirmed the airway with a bronchoscopy and attempted suctioning of tracheal and bronchus secretion. However, his left lung was worsening rapidly, and severe hypoxia $\left(\mathrm{FiO}_{2} \quad 0.5, \mathrm{PaO}_{2} 69.4 \mathrm{mmHg}\right)$ was due to aspiration of PI. The PI solution permeated into alveoli of the lung and inflicted atelectasis. Although the patient progressed to severe pulmonary diseases and ARDS, the patient recovered without severe complication. We suggest the result was possible because PI solution was diluted $10 \%$ to a few $\%$ by saline irrigation. And, we inspected directly and suctioned the PI solution through a bronchoscopy when respiratory abnormality was suspected.
If we disinfect an oral cavity with PI solution, we should take precautions for aspiration pneumonia. First, we will not swill out with PI solution, but wipe a surface with diluted PI. Next, patient undergoing a general anesthetic would be a throat-pack placed before an oral preparation. And during the preparation, positive intrathoracic pressure was ensured by the anesthesiologist. Even more, a head-down tilt of 15 to $20^{\circ}$ for the head to neck orientation was optimal for minimizing tracheal and bronchial aspiration [26].

PI solution will be commonly used for an antiseptic with surgery. But, various \% of a pulmonary instilled PI solution can induce lung injury. When using PI solution for oral disinfection, we should always consider the possibility of pulmonary aspiration and be cautious to prevent aspiration pneumonia. If pulmonary aspiration occurs, we will use a bronchoscopy for careful inspection and appropriate treatments.

\section{Compliance with ethical standards}

Conflict of interest The authors declare that they have no conflict of interest.

Ethical approval The patient reads and signs an informed form.

Informed consent Written informed consent was obtained from the patient for publication of this case report.

Statement of authors All authors have viewed and agreed with this present submission.

\section{References}

1. Rahn R (1993) Review presentation on povidone-iodine antisepsis in the oral cavity. Postgrad Med J 69:4-9

2. Durani P, Leaper D (2008) Povidone-iodine: use in hand disinfection, skin preparation and antiseptic irrigation. Int Wound J 5:376-387

3. Sauerbrei A, Wutzler P (2010) Virucidal efficacy of povidoneiodine-containing disinfectants. Lett Appl Microbiol 51:158-163

4. Howe DJ (1981) Aspiration pneumonia from povidone-iodine (Betadine): report of case. J Oral Surg 39:224-225

5. Numazawa R, Morimoto Y, Yokota S, Yamamura T, Kemmotsu O (1992) Pneumonia due to aspiration of povidone-iodine during anesthesia: a case report. Masui 41:846-849

6. An TH, Ahn BR (2011) Pneumonia due to aspiration of povidine iodine after induction of general anesthesia. Korean J Anesthesiol 61:251-256

7. Cheong SH, Yang YI, Choi MY, Kim MH, Cho KR, Lim SH, Lee JH, Lee KM, Moon SH (2012) Lung injury induced by the pulmonary instillation of povidone-iodine in rats. J Anesth 26:70-79

8. Engelhardt T, Webster NR (1999) Pulmonary aspiration of gastric contents in anaesthesia. Br J Anaesth 83:453-460

9. Olsson GL, Hallen B, Hambraeus-Jonzon K (1986) Aspiration during anaesthesia: a computer-aided study of 185,358 anaesthetics. Acta Anaesthesiol Scand 30:84-92

10. Warner MA, Warner ME, Weber JG (1993) Clinical significance of pulmonary aspiration during the perioperative period. Anesthesiology 78:56-62 
11. Chawla R (2008) Epidemiology, etiology, and diagnosis of hospital acquired pneumonia and ventilator-associated pneumonia in Asian countries. Am J Infect Control 36:93-100

12. Dave MH, Frotzler A, Spielmann N, Madjdpour C, Weiss M (2010) Effect of tracheal tube cuff shape on fluid leakage across the cuff: an in vitro study. Br J Anaesth 105:538-543

13. Nagatake T, Ahmed K, Oishi K (2002) Prevention of respiratory infections by povidone-iodine gargle. Dermatology 204:32-36

14. Wutzler P, Sauerbrei A, Klöcking R, Brögmann B, Reimer K (2002) Virucidal activity and cytotoxicity of the liposomal formulation of povidone-iodine. Antivir Res 54:89-97

15. Dire DJ, Welsh AP (1990) Comparison of wound irrigation solutions used in the emergency department. Ann Emerg Med 19:704

16. Johnson JT, Yu VL (1989) Role of aerobic gram-negative rods, anaerobes, and fungi in wound infection after head and neck surgery: implications for antibiotic prophylaxis. Head Neck 11:27-29

17. Becker GD (1981) Chemoprophylaxis for surgery of the head and neck. Ann Otol Rhinol Laryngol Suppl 90:8-12

18. Summers AN, Larson DL, Edmiston CE, Gosain AK, Denny AD, Radke L (2000) Efficacy of preoperative decontamination of the oral cavity plast. Reconstr Surg 106:895-900

19. Grandis JR, Vickers RM, Rihs JD, Yu VL, Johnson JT (1994) Efficacy of topical amoxicillin plus clavulanate/ticarcillin plus clavulanate and clindamycin in contaminated head and neck surgery: effect of antibiotic spectra and duration therapy. J Infect Dis 170:729-732
20. Redleaf MI, Bauer CA (1994) Topical antiseptic mouthwash in oncological surgery of the oral cavity and oropharynx. J Laryngol Otol 108:973-979

21. Choi SH, Lee SJ, Yoon KB, Han S, Kim JH (2005) Fiberoptic bronchoscopic treatment of pulmonary aspiration occurring in a child during induction of anesthesia -a case report. Korean J Anesthesiol 49:744-747

22. Nason KS (2015) Acute intraoperative pulmonary aspiration. Thorac Surg Clin 25:301-307

23. Paulson TE, Spear RM, Silva PD, Peterson BM (1996) Highfrequency pressure-control ventilation with high positive endexpiratory pressure in children with acute respiratory distress syndrome. J Pediatr 129:566-573

24. Meduri GU, Marik PE, Annane D (2009) Prolonged glucocorticoid treatment in acute respiratory distress syndrome: evidence supporting effectiveness and safety. Crit Care Med 37:1800-1803

25. Calfee CS, Matthay MA (2007) Nonventilatory treatments for acute lung injury and ARDS. Chest 131:913-920

26. Takenaka I, Aoyama K, Iwagaki T (2012) Combining head-neck position and head-down tilt to prevent pulmonary aspiration of gastric contents during induction of anaesthesia: a volunteer and manikin study. Eur J Anaesthesiol 29:380-385

Publisher's note Springer Nature remains neutral with regard to jurisdictional claims in published maps and institutional affiliations. 